\title{
公路工程汸青路面施工技术和质量控制分析
}

\author{
周海峰 \\ 南通万达公路养护工程有限公司 \\ DOI:10.32629/btr.v2i10.2541
}

[摘 要] 随着社会经济的不断发展, 国内公路工程建设数量越来越多,沥青路面具有施工流程简单、取材方便等优势特征,目前 在公路工程施工中应用十分广泛, 它能够为驾驶人员提供一个舒适、安全的行车环境。本文主要对公路工程励青路面施工技 术和质量控制进行了研究。

[关键词] 公路工程；沥青路面；施工技术；质量控制

沥青路面施工是公路工程中的重要组成部分, 实践过程 中, 主要就是利用沥青混合料对公路路面进行铺筑, 沥青属 于一种有机胶凝材料, 具有良好的防腐性和防潮性, 目前在 公路工程施工中应用十分广泛。沥青路面不仅表面平整, 且 后续维护相对简单、便捷, 但实践过程中, 必须要对相关的施 工技术进行明确掌握, 同时还要强化对施工质量的控制, 这 样才能最大限度发挥出沥青路面的优势特征, 促进我国公路 事业的健康稳定发展 ${ }^{[1]}$ 。

\section{1 沥青路面特点分析}

与普通路面不同, 沥青路面很容易受到多种因素的影响, 例如, 水、温度等。在具体施工过程中, 沥青路面主要就是在 刚性或者半刚性基层上对沥青混合料进行铺设, 由于材料自 身的特点, 因此在很多情况下都会对公路施工产生影响。为 避免上述问题, 必须要强化对材料自身性质的控制, 例如, 在 高温和汽车压力的作用下, 很容易使路面出现变形的问题, 为此, 在施工过程中, 一般可将适量粗集料加入到沥青中, 以 提升材料的摩擦力, 使路面的空间结构更加稳定。

此外, 低温也会影响公路工程施工, 在低温状态下, 路面 很容易出现开裂的问题, 从而影响整体的路面结构, 对于上 述问题, 一般可通过应用改性沥青和增加沥青浓度的方式进 行预防 ${ }^{[2]}$

水也会对公路运行产生影响, 通常表现在沥青的乳化作 用方面, 在水的影响下, 公路结构会逐渐软化, 同时也会对其 粘合力产生影响, 破坏路面结构, 鉴于上述情况, 一般可通过 改性剂的应用加以缓解, 提升路面结构稳定性。

\section{2 公路工程沥青路面施工技术}

2. 1 混合料配比技术

在对沥青混合料进行生产之前, 必须要进行配合比设计, 通过目标配合比设计、生产配合比设计及生产配合比验证来 确定混合料中各类材料用量、拌合时间、温度、工艺等, 使 得混合料的各项指标符合设计文件和规范的相关要求。

2. 2 沥青摊铺技术

在公路工程现场施工过程中, 沥青路面的摊铺需本着循 序渐进的基本原则, 连续、均匀、缓慢的进行摊铺, 以确保该 工作的顺利开展, 摊铺速度应保持在每分钟 $2^{\sim} 6 \mathrm{~m}$ 。沥青摊铺
施工需要由专业人员进行监督和指挥, 以保证该工作的连续 性, 如无特殊情况, 一般不能中途停止。完成摊铺之后, 需要 对路面质量进行及时检查, 使施工能够更好的满足建设要求, 对于混合料不均匀、坑槽较多或混合料散乱的地段, 通常要 进行重新摊铺。下层路面摊铺时, 可每相隔 $5 \mathrm{~m}$ 的距离就要设 置一个钢丝支架, 钢丝拉力要在 $800 \mathrm{~N}$, 直径也要大于 $6 \mathrm{~mm}$, 这 样更加有助于控制摊铺质量, 同时也能为后续的碾压工作奠 定良好基础 ${ }^{[3]}$ 。上层沥青路面摊铺时, 宜采用平衡梁等自动 找平装置控制摊铺厚度、平整度。

\section{3路面碾压技术}

在完成沥青路面摊铺之后, 需要开始对路面进行碾压, 速度一般要保持在每小时 $2^{\sim} 4 \mathrm{~km}$, 沥青路面碾压主要包括三 个环节, 即初压、复压、终压, 完善做好各环节碾压工作, 能 够为工程建设质量提供保障。在公路工程施工过程中, 初压 需要使用双钢轮振动压路机 (13t) 进行静压, 碾压一遍即可, 速度保持在每小时 $2 \mathrm{~km}$ 左右, 之后进行复压。复压需要使用双 钢轮振动压路机和轮胎式压路机的组合进行碾压, 双钢轮压 路机一般需要碾压三遍, 震动频率要保持在 $40 \sim 50 \mathrm{~Hz}$, 速度控 制在每小时 $3 \mathrm{~km}$ 左右, 之后再使用轮胎式压路机进行碾压, 速 度同上。在终碾环节, 主要是使用一台双钢轮振动压路机进行 碾压 1 2 次, 速度控制在每小时 $3 \mathrm{~km}$ 左右。为保证碾压质量和 效果, 可在碾压过程中使用不同标识对初压、复压、终压进 行清晰标注, 以免出现漏压、重复碾压的问题。与此同时, 还 需要妥善做好车道变换工作, 避免对沥青路面产生破坏。在路 面稳定、混合料连接紧密、无下沉现象出现、路面平整、无 轮迹时再停止碾压。

在公路工程沥青路面施工过程中, 为确保工程建设质量, 相关施工人员必须要严格按照规范做好混合料压实工作, 与 此同时, 还需要按照要求对混合料进行科学配比, 上述任何 一项工作存在缺陷, 都会对工程建设质量产生影响, 从而为 公路运行带去负面影响。在高等级沥青路面施工中, 还需要 通过试验段路面的施工对机械设备组合进行合理选择, 为沥 青路面的耐久性和压实度提供保障 ${ }^{[4]}$ 。

2. 4 路面接缝施工技术

在公路工程沥青路面施工中, 横向裂缝和纵向裂缝问题 
十分常见, 这些问题的产生都会对工程建设质量产生影响。对 于纵向施工缝, 一般可使用摊铺机进行处理, 同时在已完成 摊铺的混合料中预留出 $10^{\sim} 20 \mathrm{~cm}$ 距离不做压实处理, 摊铺层 重叠区域约 $5^{\sim} 10 \mathrm{~cm}$, 此时可通过热接缝的方式进行碾压, 以 去除接缝。对于横向施工缝, 可采用平接缝的方式进行处理, 同时也可通过钢筒式压路机设备进行横向碾压, 实现对接缝 的有效处理, 提升公路工程沥青路面施工质量。

\section{3 公路工程沥青路面施工质量控制措施}

在公路工程沥青路面施工过程中, 施工人员不仅要对相 关施工技术进行明确掌握, 同时还需要掌握一些施工质量控 制措施, 从而大幅度提升工程建设质量 ${ }^{[5]}$ 。

3. 1 强化施工材料管理

在公路工程沥青路面施工过程中, 施工材料占据着十分 关键的地位, 具体如集料、石屑、机制砂、矿粉、沥青等, 这些材料在正式应用之前, 都要进行严格的检测, 对于检测 不合格的材料一律禁止应用。另外, 还要对材料采购进行严 格控制, 要优先选择资质齐全、信誉良好且产品质量好的厂 家, 不能为了节约成本而选择劣质材料。总之, 只有保证施工 材料质量, 才能工程建设质量提供保障。

3.2 强化对施工机械设备的检查

施工设备也是公路工程沥青路面施工中的关键性内容, 在施工之前, 必须要强化对施工机械的检查, 以保证其性能 良好。对于碾压设备、推铺设备、运输设备等, 也要进行系 统化检查, 确保其性能良好、零部件齐全, 这样才能为施工效 率的提升提供保障。另外, 对于大型机械设备, 还要强化维修 和保养, 这些设备用一旦出现故障, 不仅需要花费大量维修 成本, 同时也会对正常施工产生影响, 其安全性能也将会大 幅度降低, 因此, 必须要定期对大型机械设备进行检查, 发现 问题及时处理, 以免对施工质量产生影响 ${ }^{[6]}$ 。

3. 3 强化施工质量检测和评定

施工质量评定和检测的内容主要包括原材料质量、混合 料温度、沥青面层质量等。通过温度检测, 可确保混合料拌 合温度适宜, 从而更好的满足工程施工要求; 材料检测, 能够 为施工材料质量提供保障; 配合比检测, 可以使沥青混合料
处于合理的级配区间; 沥青面层检测, 能够做到发现问题及 时解决, 实现对相关数据的及时有效分析, 从而更加全面的掌 握和了解路面质量情况, 对沥青路面进行动态化控制和管理。

3. 4提升施工人员的专业素养

在公路工程沥青路面施工中, 为了提升工程建设质量, 还要不断提升施工人员的专业素养和技能水平, 使其明确掌 握各种现代化先进技术, 并对其进行灵活应用, 提升人员的 责任意识, 从而能够在施工中发现及时解决, 若不能解决也 会在第一时间向上级部门汇报。要想实现上述目标, 还要强 化对施工人员的教育与培训, 提高施工团队的专业素养, 如 此才能够为公路工程沥青路面施工质量提供保障 ${ }^{[7]}$ 。

\section{4 结束语}

综上所述, 在公路工程沥青路面施工中, 为确保工程建 设质量, 施工人员不仅要明确掌握各种施工技术, 同时还要 能够合理应用施工质量控制措施。实践过程中, 施工人员可 结合工程建设要求, 选择合适的施工技术, 强化对各施工环 节的质量控制, 发现问题及时解决, 在保证施工活动顺利开 展的同时, 大幅度提高工程建设质量。

\section{[参考文献]}

[1]张跃华,何路沝.浅析公路工程沥青路面施工技术与 质量控制 $[\mathrm{C}] / /$ 决策论坛——企业精细化管理与决策研究学 术研讨会,2015.

[2]李智,张肖宁,雷尊贵,等.激光纹理仪在广惠高速公路 沥青路面施工中的应用 [J].湖南交通科技,2006,32(3):94-96.

[3]丁勇强,陈新轩.振荡压实技术在沥青路面施工中的 可行性分析[J]. 筑路机械与施工机械化,2007,24(6):50-52.

[4]席晓涁.高速公路涊青路面施工中离析现象的成因及 防治措施[J].交通建设与管理,2014,(8):128-129.

[5]魏邦贵.城市道路SMA沥青路面施工的技术难点及控 制措施[J].西部探矿工程,2010,22(11):230-232.

[6]李斌.公路工程沥青路面施工质量管控及实践举措研 究[J].城市建设理论研究(电子版),2017,(24):172-173.

[7]陈健,苑春武,陈丽娟.公路工程沥青路面施工技术及其 质量控制模式的优化[J].中国新技术新产品,2013,(19):41-42. 